Original Research Paper

\title{
Vulnerability and Protection of Glass Windows and Facades under Blast: Experiments, Methods and Current Trends
}

\author{
${ }^{1}$ Xihong Zhang and ${ }^{2}$ Chiara Bedon \\ ${ }^{1}$ Centre for Infrastructure Monitoring and Protection, \\ School of Civil and Mechanical Engineering, Curtin University, Bentley, Australia \\ ${ }^{2}$ Department of Engineering and Architecture, University of Trieste, Trieste, Italy
}

Article history

Received: $10-07-2017$

Revised: 20-07-2017

Accepted: 24-07-2017

Corresponding Author:

Chiara Bedon

Department of Engineering and Architecture, University of

Trieste, Trieste, Italy

Email: chiara.bedon@dia.units.it

\begin{abstract}
Glass has been overwhelmingly used for windows and facades for modern constructions. Nevertheless, due to its relatively low tensile strength and mostly brittle behaviour, compared to other structural members, glass windows/facades are one of the most fragile components for a building envelop that are always associated with vast casualties in a blast incident. Several researches have been carried out to study the performance of glass windows and facades under blast loading, which include laboratory investigations on glass dynamic properties; analytical solutions for the analysis of the response of monolithic and laminated glass panes under shock; numerical modelling of window vulnerability to air blast waves; laboratory or field blast tests to validate the prediction and performance of glass windows and assemblies, as well as the efficiency of possible mitigation and retrofitting solutions for novel or existing glass claddings. This paper presents a review on the state of art of analysis and design of glass window/facade system under blast loading, with evidence of available experimental outcomes, design methods and trends, open challenges.
\end{abstract}

Keywords: Monolithic Glass, Laminated Glass, Vulnerability and Protection, Experiments, Dynamic Material Properties, Blast, Mitigation, Retrofit

\section{Introduction and Motivation}

Glass is an omnipast material which has been popularly used for windows and facades. Because of the relatively weaker strength of glass as material for construction, as compared with other traditional structural materials such as concrete and steel, glass elements and windows in particular are typically fragile components and therefore highly vulnerable to extreme loads such as air blast waves or hazards in general. As a result, specific fail-safe design rules are required for glass systems, even under ordinary loads (Feldmann et al., 2014). At the same time, it is necessary to properly understand the actual behaviour of glass windows and claddings especially under exceptional actions - being representative of the first line of defense from outside - as well as to opportunely design or strengthen them, to be blast-resistant and ensure human and property protection.

In most of the cases, blast events are so destructive that glass fragments and shatters are thrown away for hundreds of meters from the detonation source, hence representing the first issue to be addressed. In terms of protective and fail-safe design purposes, the combined effect of blast loading features, together with potentially related failure mechanisms in building components as well as with glass intrinsic properties, however, typically manifests in the form of many different types of possible injuries on people, some of which may be also initially occult (Wightman and Gladish, 2001). For instance, in 1986 the accidental gas explosion in Texas shattered glass windows within a radius of $800 \mathrm{~m}$. The 1995 Oklahoma City bombing attack broke windows and shattered fragments about $1000 \mathrm{~m}$ away from the explosion source. Similarly, the 2004 Jakarta terrorist bombing on the Australian Embassy (Fig. 1a) resulted in glass window shattering even in buildings $500 \mathrm{~m}$ from detonation. In 2015, the accidental explosion in Tianjin (China) shattered glass windows as far as $8.5 \mathrm{~km}$ away from damaged buildings (Fig. 1b). 


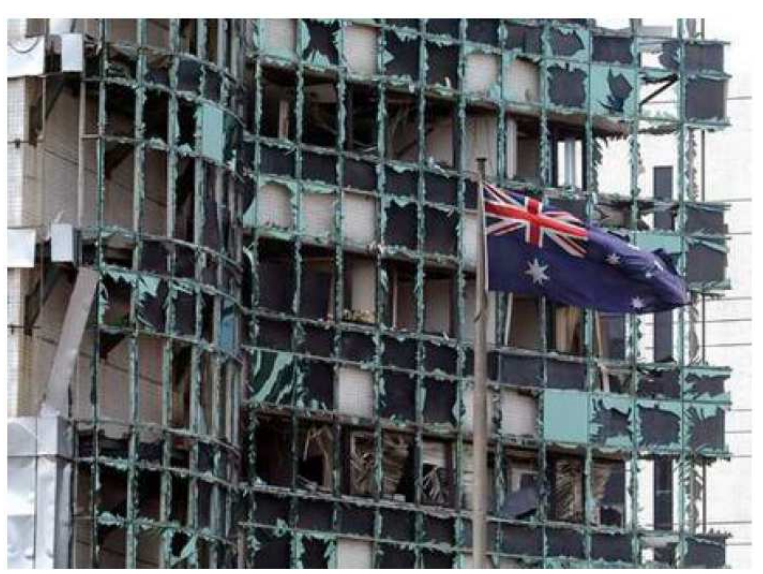

(a)

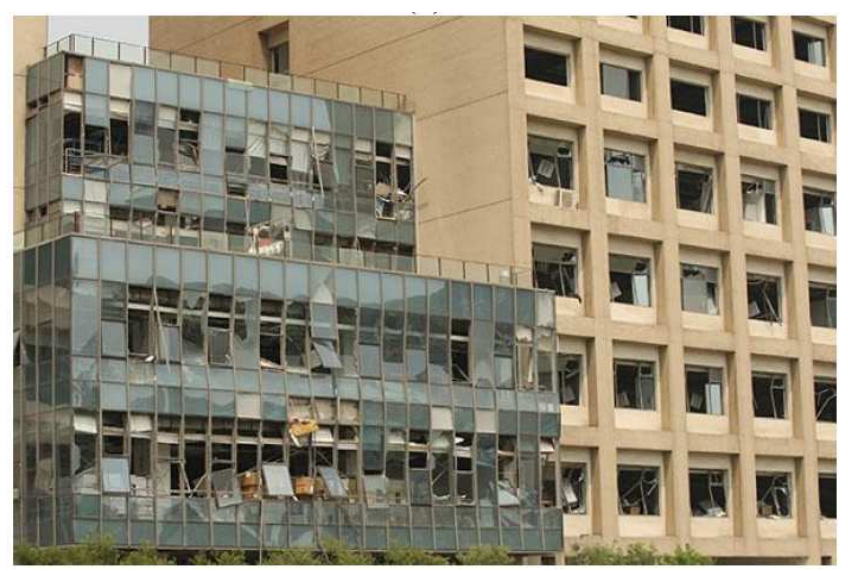

(b)

Fig. 1. Shattered glass windows. Examples referred to (a) the Australian Embassy in Jakarta, 2004 (photo by AP) and (b) Tianjin (China) explosive event, 2015, with evidence of framing systems ejection (photo by Wang Zhuangfei/China Daily)

Significant mass-casualties are mostly associated with the brittle failure of glass window panels, but also with severe damage or collapse of supporting and restraining components (Fig. 1b), with evidence of ejected framing members). From a medical point of view, penetrating fragments and debris are commonly classified as "secondary" blast injuries, while victims due to blastinduced structural collapses are conventionally classified as "tertiary" injuries, being representative of part of generally more complex and tragic emergency scenarios (Yeh and Schecter, 2012). As far as glass windows and claddings are able to act as protective barriers towards the incoming blast pressure, however, also the so called "primary" blast injuries deriving from the pressure wave can be potentially minimized. For example, the post-event investigation of the 1995 Oklahoma City bombing attack found that 198 people in buildings within a radius of $970 \mathrm{~m}$ suffered direct glass-related injuries such as lacerations and abrasions from glass shards and 265 suffered certain degree of hearing impairment owing to blast pressure penetrating the rooms from broken windows. Similarly, 9 victims and over 150 injuries were reported after the 2004 Jakarta terrorist bombing attack on the Australian Embassy. In the 2011 Norway attack, almost all the glass windows of the Oslo executive government building were shattered, which resulted in 209 (out of a total 325) injuries from glass lacerations.

Based on the continuously increasing use of glass in buildings, as well as the higher frequency of tragic accidental or human-induced blast events, several research studies have been focused during last years on the experimental, analytical and numerical investigation of glass windows and facades under blast. Careful consideration was given to material characterization, as well as to the vulnerability assessment of full glazing assemblies under impact, or to the feasibility study of possible retrofitting techniques able to enhance the overall performance of glass systems exposed to high strain rate extreme loads such as blast waves. In this study, a recapitulation of actually available research efforts is provided, with special evidence for experimental findings as well as current trends for mitigating blast-related hazards on glass windows and curtains.

\section{Fundamental of Explosions and their Effects on Structures}

Explosions consist in rapid and wild release of energy in the form of shock wave, light, heat and sound. These shock waves consist of highly compressed air traveling at supersonic velocity. When shock waves hit the frontal surface of a structure or building, they are then reflected and amplified.

As also in accordance with earlier theoretical formulations, given an explosive event, the magnitude of the overall incident blast pressure is a function of the charge weight, geometry and stand-off distance from the centre of the charge to the wave front. The magnitude of the reflected pressure is related to the incident blast pressure and to the angle of incidence. Such a pressure decays then rapidly, generally in terms of milliseconds to ambient, which becomes negative in value due to a vacuum created by the shock front resulting in suctions. Figure 2 shows the typical blast pressure time history (incident and reflected) recorded on the frontal elevation of a target structure.

In terms of structural design and analysis of blast targeted systems, empirical methods are conventionally used (see (Karlos and Solomos, 2013) for comparative case studies). In any case, shock waves are generally recognized as the primary cause of damage and failure of structural components under explosive events. The reflected overpressure of blast 
waves acting on buildings could be in fact several orders of magnitude higher than the designed loading capacity, but acting for only a few milliseconds. As such, dynamic analyses or equivalent static analyses are normally required to predict their response and to determine the corresponding vulnerability.

In the specific case of buildings designed to resist ordinary loads only, air-blast waves generally impinge on the external envelopes, leading to the failure of glass windows and facades, then entering the buildings and resulting in possible damage or even collapse of columns, beams and slabs. In some conditions, progressive collapse of the building could be also triggered.

\section{History of Blast-Related Studies on Glass Windows}

First research studies focused on the vulnerability of glass windows and associated fragment threats under blast loading date back to 1940 s, during wartime, with a large quantity of blast tests carried out (see for example (Philip, 1945)). Vulnerability curves of monolithic glass windows were derived which defined the TNT charge weight and stand-off distance of a blast wave that would break or shatter a glass window. Substantial research was conducted by US Navy and NASA, to study the blast resistant capacity of monolithic glass windows against accidental explosions during 1980s (Moore, 1980; Pritchard, 1981). Finite element method was also preliminary employed and advanced the analysis.

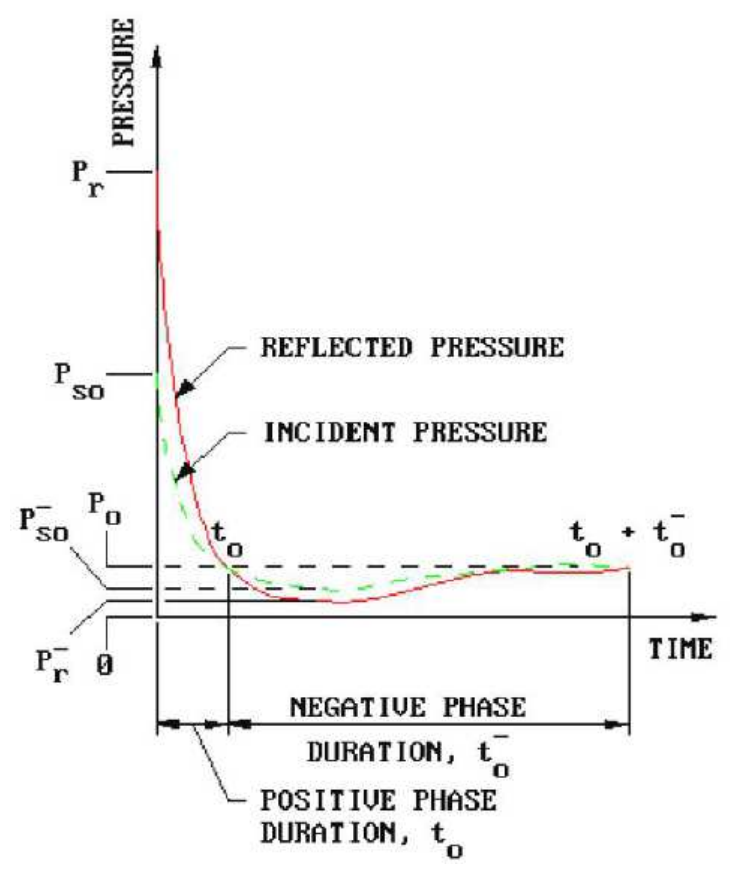

Fig. 2. Typical pressure time history, with evidence of incident and reflected pressure (UFC 3-340-02, 2008)
The concept of Laminated Glass (LG) was then introduced as early as 1940s. So far, an additional plastic film was attached to monolithic glass panes to improve the post-breakage performance. During 1980s and 1990, investigation on blast-resistant LG windows was boosted in the wake of the Irish terrorism bombing attacks on British barracks. Empirical design procedures were drafted by the UK government (HOSDB, 1997). Because these design curves were obtained from limited number of field blast testing results, however, only limited window size and dimensions were available in design charts.

With daily increased threats from terrorist bombing attacks and accidental explosions, more and more researches and studies have been carried out from 2000s on the behaviour of glass window systems under blast loading. Part of these studies are recalled and commented in the following sections, giving evidence of major outcomes and current issues to be solved.

\section{Glass Material Properties}

In order to properly assess and enhance the response of glass windows under blast, it is firstly necessary to understand the behaviour of glass as constructional material. Glass is an amorphous solid which is also a complex material. There, its mechanical properties are influenced by both chemical composition and manufacturing process. Glass is made by heating a mixture of raw minerals above transition temperature and then slowly cooled down after floated on top of molten tins. Construction-used window glass normally adopts soda-lime glass comprising about $72 \% \mathrm{SiO}_{2}$. With higher $\mathrm{SiO}_{2}$ mass ratio (around $81 \%$ ), borosilicate glass exhibits better temperature resistance (Haldimann et al., 2008).

Window glass is mainly categorized by its manufacturing process. For instance, the standard float process produces Annealed Glass (AN) which has low tensile strength (45 MPa its characteristic nominal value) but is also relatively economic. Heating and cooling AN glass produces Heat-Strengthened glass (HS), which has higher tensile strength (70 MPa the nominal value) and takes advantage of production residual stresses in the form or typical crack propagation and fragmentation, compared to AN glass. Heating AN glass to above $700^{\circ} \mathrm{C}$ and cooling it produces finally the so called Fully Tempered (FT) glass, with nominal tensile resistance in the order of $120 \mathrm{MPa}$ and typically small and smoothed fragments, hence more resistant than AN glass and also less hazardous in case of cracking. Because of the compressive stress introduced to glass pane surface, the flexural tensile strength of FT glass is in fact generally four to five times higher than that of AN glass. Due to elastic energy stored during the tempering process, even single cracks in a given FT glass pane can lead to continuous cracking associated to small and fine glass cubicles, rather than few and sharp shards (Haldimann et al., 2008). 


\section{Dynamic Characterization}

Since the stress distributions in HS and FT glass are not uniform (i.e., parabolic distribution deriving from initial residual stresses), studies on window glass material properties normally concentrate on AN glass only. As known, the behaviour of annealed glass under static loading is linear elastic and brittle. The theoretical tensile strength of glass is over $20 \mathrm{GPa}$. Nevertheless, because of the existence of surface flaw (Griffith, 1921) construction-use window glass normally breaks below $100 \mathrm{MPa}$. A Weibull distribution or normal distribution is normally utilized to describe the uncertainties in glass tensile strength.

Glass behaves very differently under dynamic loading. Under dynamic compression, the influence of surface flaw becomes less important because from micro-structure perspective, the roots of surface flaws on glass are subjected to stress corrosion from moisture. Under dynamic compression there is not sufficient time for existing cracks to propagate. Bulk failure in glass is expected to be formed, instead. Past analytical derivations found that the strength of glass could be amplified by up to 3 times under dynamic loading (Brown, 1974). Recent laboratory tests on glass cylinders also experimentally proved the dynamic increase effect on the strength of commercially used float glass, hence Dynamic Increase Factor (DIF, in the following) values have been derived from laboratory test results (Zhang et al., 2012), Fig. 3b. Design codes such as the British standard (BS EN 572-1, 2004) also recommends considering a certain dynamic increase effect $(\mathrm{DIF}=1.78)$ for glass strength in blastresistant design.

Nevertheless, contradict conclusions were reported by some researchers about such dynamic increase effect on glass strength. For instance, Holmquist et al. (1995) found only negligible dynamic increment to glass compressive strength at strain rate of $250 \mathrm{~s}^{-1}$. Peroni et al. (2011) tested finely grinded glass specimens and generally found negligible dynamic increment of resistance, as well. The latter finding was probably observed because the influence of existing flaw was minimized on the finely grinded or acid flushed glass specimens. In other words, the dynamic increase effect induced by specimen structure could be minimized when finely grinded or chemical flushed glass specimens are tested.

Dynamic tensile strength of glass material has also been studied in the meanwhile. Different testing methods including indirect Split-tensile test (Brazilian test), (Zhang et al., 2012) and Fig. 3a, three-point flexural bending tests (Nie et al., 2007) and bi-flexural ring-onring tests (Nie et al., 2010) have been utilized. Surface condition of test specimens such as roughness, existing flaw have been found to still play an important role to the dynamic tensile strength of glass material. It is worth noting that despite of the existing studies considering the large variation observed in glass static tensile strength, more study is still needed to properly understand glass dynamic tensile strength.
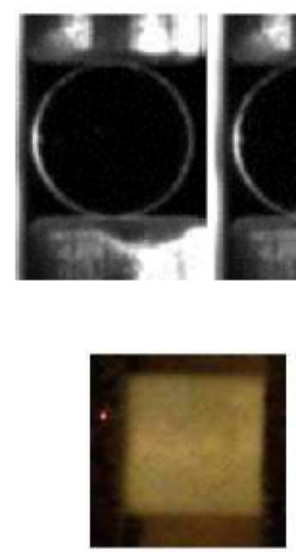

$\mathrm{t}=0.00 \mu \mathrm{s}$

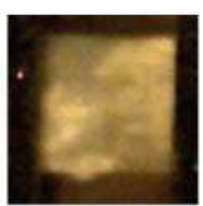

$\mathrm{t}=78.22 \mu \mathrm{s}$
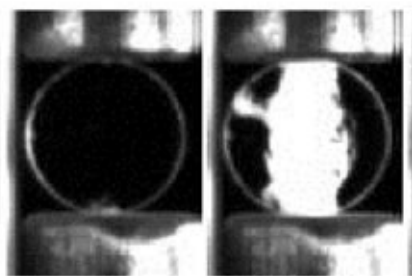

(a)
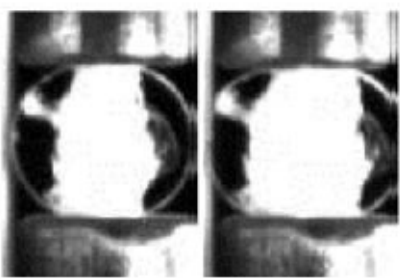

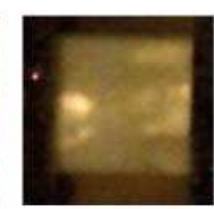

$\mathrm{t}=21.08 \mu \mathrm{s}$

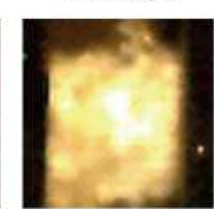

$t=149.65 \mu \mathrm{s}$

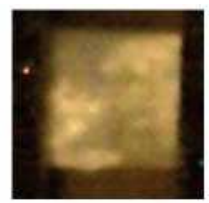

$t=69.65 \mu \mathrm{s}$

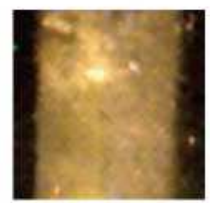

$t=278.49 \mu \mathrm{s}$

(b)

Fig. 3. Dynamic material testing on glass. (a) Splittensile tests using SHPB (Peroni et al., 2011); (b) uni-axial compression testing using SHPB (Zhang et al., 2012) 


\section{Experimental Studies on Glass Windows under Blast}

A large amount of experiments have been carried out on glass windows under blast loading. Nevertheless, for security concern, most of these tests are still confidential and not for public access. This chapter, as a result, summarizes only popularly cited experimental works on monolithic and LG windows.

\section{Monolithic Glass Windows}

Many field blast tests and shock tube tests have been performed over the years. For instance, Meyers et al. (1994) carried out shock tube tests on monolithic FT glass windows with squared and rectangular panes. Weissman et al. (1978) tested monolithic AN glass windows with aluminium or wood frame. The windows were arranged either face-on or side-on the direction of blast wave. Zhang et al. (2015a) performed full-scale blast test on monolithic FT glass windows. Glass window deformation-to-fracture processes were monitored in detail using high-resolution high-speed cameras. Ge et al. (2012) carried out field blast tests on monolithic AN glass windows to investigate fragment behaviour.

It should be noted that many commercial blast tests have also been carried out in the meanwhile. But these tests are relevant and addressed only to validate particular mitigation products and methodologies, or to evaluate their efficiency, rather than investigating the blast-related phenomena of a given specimen or deriving general observations.

A recent study, for example, found monolithic glass windows break in two unique failure modes:

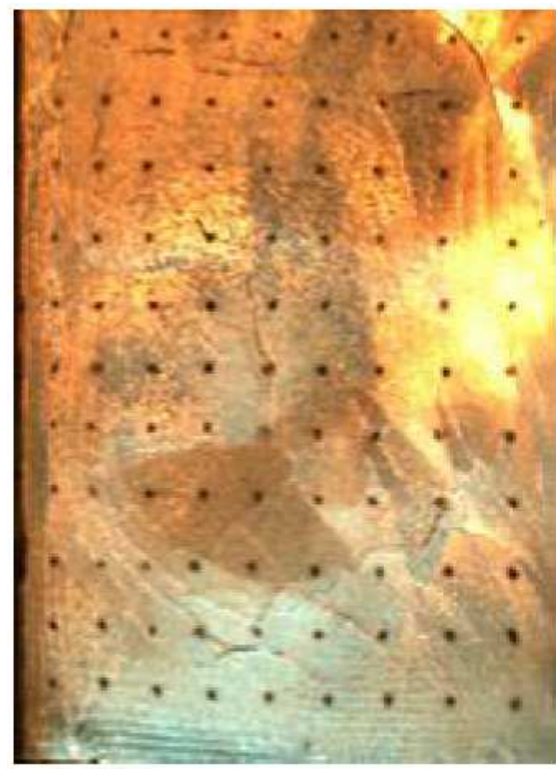

(a)
Planer failure and spherical failure mode, Zhang et al. (2015a) and Fig. 4. When the duration of air blast wave acting on the glass pane is relatively large, in particular, spherical failure which relates to the flexural response of the glass pane tends to be developed and prevail. When the loading duration is relatively short, conversely, planar failure which relates primarily to the shear failure mode of the glass pane is likely to occur. Similar observation was also mentioned by Morison (2010). Therefore, as a major effect of such experimental findings and outcomes, it is important to notice that commonly adopted design methods could result in unreliable predictions. This is especially the case of methods based on SDOF approaches, such as UFC 3-340-02 (2008), where only the flexural response of glass windows is considered and hence may not necessarily well predict the response of monolithic glass windows under blast loading.

\section{Vulnerability and Fragmentation Analysis: Standard Approaches and Available Methods}

As also mentioned in the Introduction, the majority of casualties in a blast incident are associated with glass fragment injuries. Design codes such as GSA TS-01 (2003), in this regard, classify glass fragments threat based on their splash distances into a given occupied area (Fig. 5). According to the GSA code, glass windows that do not break or break but managed to retain fragments within frame members are rated as "no threat". If glass fragments are supposed to fail within $1 \mathrm{~m}$ distance from the opening, the threat is rated as "very low"; when the fragments fly longer than 0.6 at $3 \mathrm{~m}$ distance, the hazard level is rated as "high".

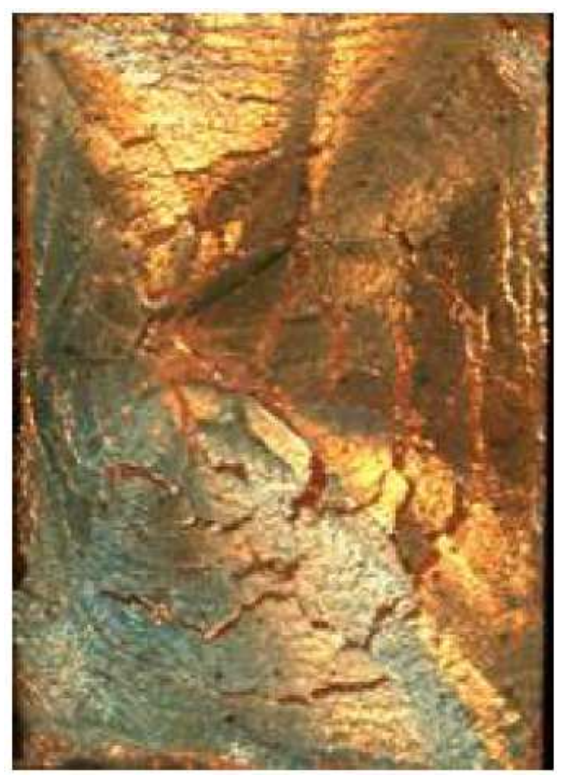

(b)

Fig. 4. Failure modes of monolithic glass windows, in accordance with (Zhang et al., 2015a); (a) Planer failure or (b) spherical failure modes 


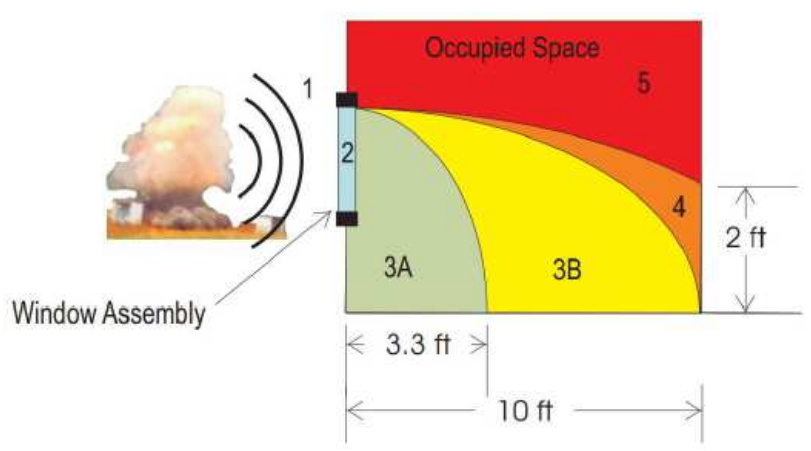

Fig. 5. Criteria of fragments threat, in accordance with GSA TS-01 (2003)

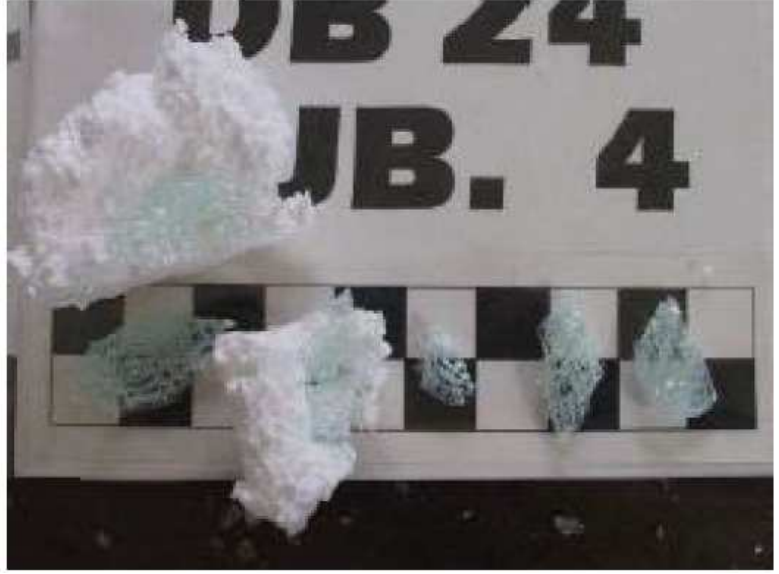

(a)

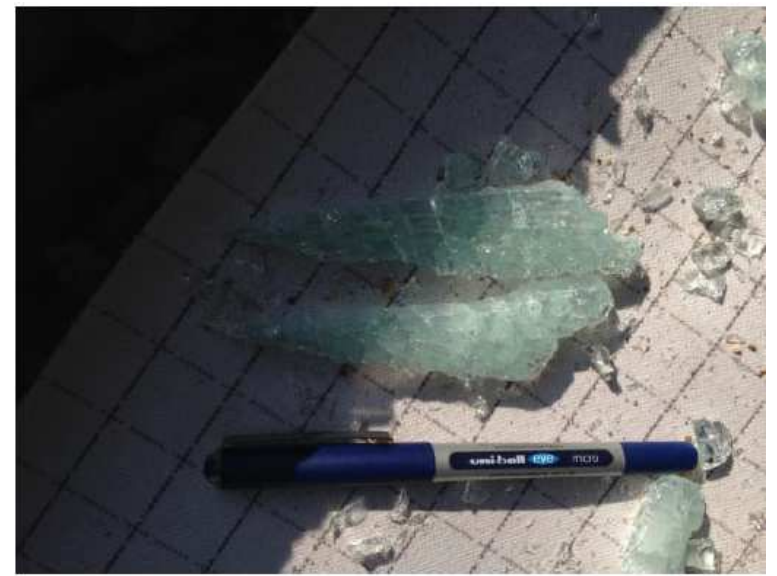

(b)

Fig. 6. Fragment of fully tempered glass from blast incidents (Zhang et al., 2014)

Mostly similar glass fragment assessment criteria are also available in other design documents, like for example ASTM F1642 (2004) ISO 16933 (2007) and the British Glazing Hazard Guide (HOSDB, 1997; Meyer et al., 2004). Nevertheless, it should be first noted that evaluations rules collected in these technical documents can be applied to glass windows with specific features and dimensions only (Bedon et al., 2015; Arrigoni et al., 2017). In addition, fragments velocity, size, shape etc. are not considered in defining the threat level in all the mentioned standards.

In this regard, many experiments related to glass fragmentation properties have been reported in the past few years. van Doormaal et al. (2009) tested AN glass windows and correlated the maximum fragment velocity with reflected overpressure and impulse. Fletcher et al. (1980) and Iverson (1968), respectively, studied fragment characteristics such as fragment velocity, mass, spatial density with reflected overpressure and assessed their biological impacts. There, it was found that the projecting distance and fragment velocity are proportional to the magnitude of reflected overpressure and impulse. Under blast loading fragment threats from FT glass windows were normally ignored, because under static loading tempered glass shatters into numerous small and fine cubicles.

Recent field tests proved, however, that FT glass could also break into large and jagged pieces under blast loading which impose considerable fragment threats to people (Zhang et al., 2014) Fig. 6. The fragments characteristics such as ejected fragment mass, fragment size, shape, number, spatial density and launching velocity were systematically studied. It is also worth noting that negative pressure was found to significantly influence fragment ejecting velocity and splash distribution, which led to glass fragments propelled and splashed in front of windows.

Reliable analytical solutions for predicting glass fragmentation, fragment size, fragment ejecting velocity are still not available yet. Some semi-analytical formulations based on energy principles in estimating fragment velocity was only recently proposed. The constants of the formulae, however, were still derived from field blast test (Ge et al., 2012).

Successful numerical models in simulating glass fragment properties, finally, are very limited. Most existing numerical methods suffer inherited deficiencies in predicting glass fragmentation process. For example, the commonly used Finite Element method could only 
employ erosion technique, which deletes elements to taken into account the reduction in stiffness due to glass progressive fracture, as well as to show the qualitative cracking pattern. In several cases, it was shown that such damage modelling approach can provide close correlation with experiments, especially in terms of macro-cracks in glass panes and overall performance of the examined glass system (Larcher et al., 2012; Bedon and Louter, 2014; Bedon and Amadio, 2016). Beside the reliability of such material damage models and their calibration and/or limits, a common issue related to potential use of finite element models to replace blast experiments in general, is still represented by total lack of guidelines and standardized rules, aimed to preserve the accuracy of predictions, as well as the correlation of observations to standard requirements (Larcher et al., 2016). Discrete element method and mesh-less method both require predefined particle size and weak sections. Numerical manifold method could avoid predefining numerical mesh but matured three dimensional model to predict glass fragmentation under out of plane blast loading is still under development. Most of current practice are therefore still based on empirical formulae derived from field tests.

\section{Laminated Glass Windows}

Laminated glass is widely used for blast resistant glazing to mitigate the hazards from ejecting glass fragments. As known, the conventional LG window is made of two or more layers of glass panes, bonded together with one or multiple plies of interlayers (Haldimann et al., 2008). The primary aim of LG is to hold shattered glass shards together and deforms with its substantial ductility as a continuous membrane to dissipate the imposed energy.

As also depicted in Fig. 7, the deformation-to-failure process of a LG pane in out-of-plane bending can be described as follow (Larcher et al. 2012; Gebbeken and Bermbach, 2014):

- Glass plies deform elastically

- The outer glass ply breaks

- The inner glass ply cracks

- The interlayer deforms as a membrane

- The interlayer fails by reaching its failure strength or by cutting of glass shards

Design codes such as UFC 3-340-02 (2008) and Glazing Hazard Guide (HOSDB, 1997) utilize SDOF method to analyse the response of LG panels under blast loading. Large deflection theory is employed to predict the response of LG panes before glass cracks, after which the LG panes could be treated as flexible membranes. The load resistance function and the equivalent load-mass factors of the LG panels are derived from testing results or through analytical calculations. The quality and reliability of predictions are therefore heftily relying on the accuracy of the adopted resistance function. For instance, a static resistance function was suggested for blast-loaded LG elements by the Glazing Hazard Guide (HOSDB, 1997).

Since the dynamic material properties of the interlayer material vary significantly from those typically considered under static loading conditions (Zhang et al., 2015c; 2015d), it has been reported that the latter method could severely underestimate the LG panels deflections, especially when the panels are subjected to large scale blast loads (Zhang et al., 2015b).

Other available design standards, including ASTM F2248-09 (2009) ASTM E1300-09 (2009) specify an equivalent $3 \mathrm{~s}$ design load for consideration of blast environments. The maximum deflections expected at the centre of a given LG pane are then estimated using Vallabhan and Chou nonlinear analysis method (Vallabhan and Chou, 1986).

Many laboratory and field blast tests were performed to study LG window responses to blast loading (Fig. 8). For instance, Kranzer et al. (2005) studied LG windows responses under low-level blast (Fig. 8a). Hooper et al. (2012) tested LG windows, giving evidence of both interlayer and boundary failure mechanisms (Fig. 8b). Zhang et al. (2015b) conducted both field blast tests and air-bag impact tests to evaluate the accuracy of available analysis and design methods. It was reported, for example, that the ASTM standard (ASTM F2248) could largely underestimate the actual LG pane response. Given a glass window to verify, UFC 3-340-02 (2008) and other SDOF-based analytical approaches (i.e., (HOSDB, 1997)) could give in fact reasonable and conservative predictions only when the level of deflections is small. When the pane deflections are large, conversely, most of the available SDOF-based methods tend to underestimate the actual pane response, because of the adoption of static resistance function.

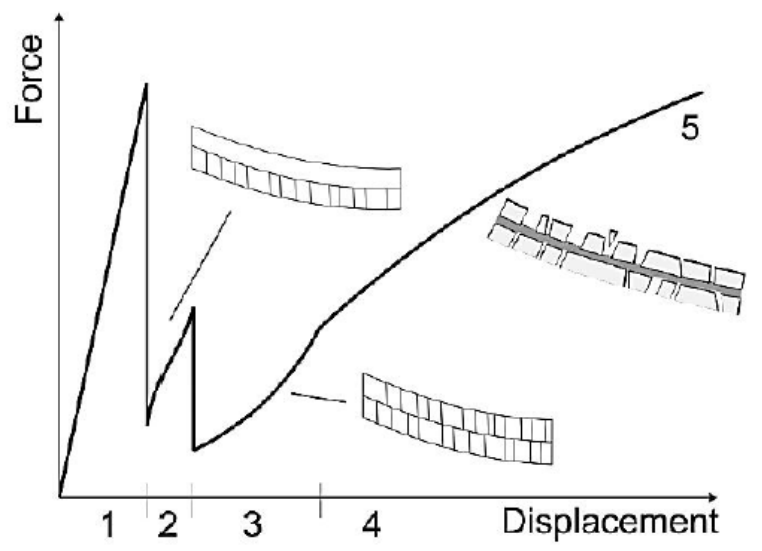

Fig. 7. Schematic deformation-to-failure process of laminated glass (Larcher et al., 2012) 


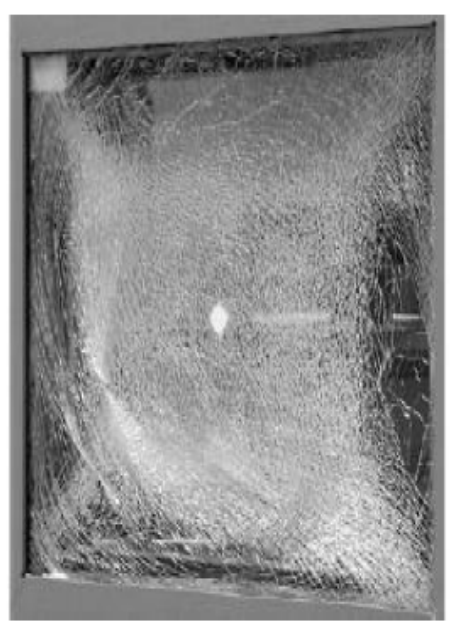

(a)

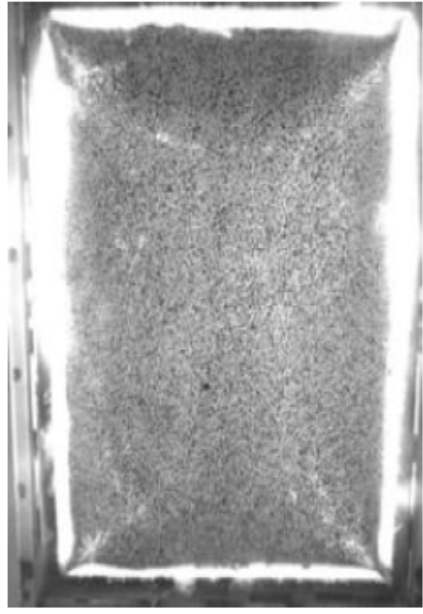

(b)

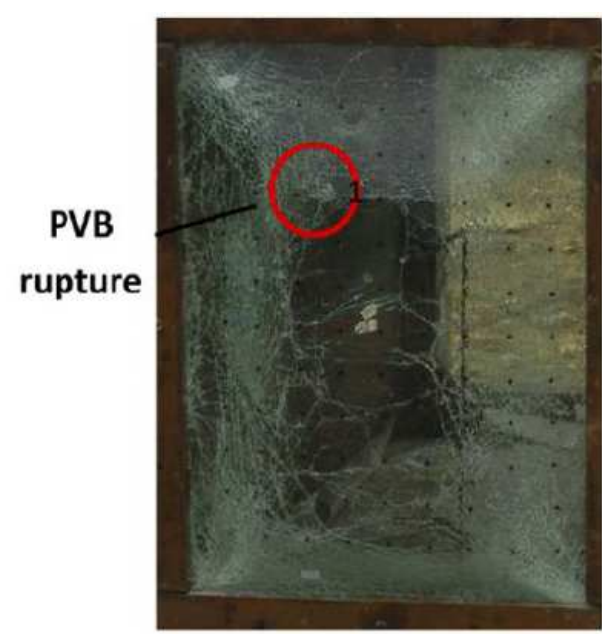

(c)

Fig. 8. Different failure modes for laminated glass windows, as observed from blast tests. (a) Glass crack only (Kranzer et al., 2005); (b) boundary failure (Hooper et al., 2012); (c) PVB rupture (Zhang et al., 2015b)

Some further observations from previously mentioned experiments are worth mentioning. Firstly, glass delamination from PVB interlayer foils is hardly a problem, as also in accordance with very limited delamination reported. Secondly, using thicker glass panes typically increase the overall LG panel flexural stiffness and inertia resistance, which improves the original blast-resistant performance of the LG window to design or verify. Thirdly, a thicker interlayer improves the LG window rupture-resistance performance, but its overall structural effect is mostly limited, especially in the pre-cracked stage. It should be also pointed out, finally, that the restraint from window frame deserves enough attention when design a LG window against blast loading. Differing from monolithic glass windows, after glass plies crack, the deformation of a given LG pane and the substantial membrane effect tend in fact to pull the cracked panel out of the supporting frame. Without the formation of interlayer tearing failure phenomena, consequently, global boundary failure mechanisms could be developed, especially when insufficient anchorage is provided for the LG system (Zhang and Hao, 2015).

\section{Mitigation and Retrofit: An Overview}

To reduce the threat from shattered glass windows and limit the associated consequence of glass window failure in an explosive incident, miscellaneous retrofitting techniques have been developed and introduced over the last years. In general, mitigation strategies include:

- Employing new materials with higher strength

- Utilizing more ductile interlayer materials for LG sandwich sections
- Strengthening and applying new techniques to window frame members, etc

In the last decades, the technology of glass facades has made good progress, for example, by utilizing glass lamination (Lin et al., 2004). The so obtained resisting cross section, composed of a plastic layer sandwiched between two glass sheets (i.e., PVB and SGP ${ }^{\circledR}$ ), has been considered for several decades the "conventional" blastresistant glazing system, since able to provide additional plasticity to typical brittle glass structures, hence guaranteeing a certain amount of post-cracked deformations and energy absorption under impact (Haldimann et al., 2008).

Beside the large use of LG in practice, recent studies emphasized the limitations of this approach (Trawinski et al., 2004), e.g., highlighting that the structural efficiency of PVB-laminated glass systems strongly depends on the thickness of glass panes (usually very thick, thus expensive) and on the mechanical properties of the interlayer foils, typically time loading and temperature dependent, hence not able to guarantee appropriate performances under extreme loads. Moreover, the collapse of the glazing system could also occur due to tearing of the same PVB-foils. In this context, several alternative solutions have been proposed and developed, including anti-shatter and blast mitigation films, curtain shield systems, cable nets, etc. Some of these possibilities are briefly summarized and commented in the following sections.

\section{Monolithic Glass}

Replacing conventional low strength AN glass with HS, FT glass of a combination has been considered, for decades, one of the most commonly adopted method to 
improve the performance of glass windows against higher lateral loading.

Applying security films including daylight films, wet glazed films and/or mechanically attached films is another popular and relatively recent mitigation and retrofitting solution for monolithic glass panes. A security film typically consists of a plastic film, 0.2 to $0.4 \mathrm{~mm}$ in thickness, which is applied on the interior surface of windows. Generally, security films do not significantly improve the original strength and stiffness of glass panes. But on the other hand, when glass panes crack as a consequence of a blast event, the applied film should be able to attach the shattered window, instead of flying as numerous fragments towards people.

In this context, security films actually represent a usual, quick in installation and relatively inexpensive retrofitting solution for existing windows and facades. Nevertheless, the protection level of applying security film is relatively low and vulnerability levels for a given glass window to retrofit can be hardly enhanced in a significant way. As a major risk for glass windows retrofitted with security films and subjected to medium or large-scale blast loadings, the entire shattered panes could in fact break along the window edges and at the frame connections, hence be propelled as whole rigid bodies into the occupied area, with consequent threats for people.

\section{Laminated Glass and Additional Tools}

Introducing LG panes in existing windows can be regarded as an extension of applying security films and replacing AN glass panes with HS of FT elements. As discussed above, the key role of interlayers between glass panes is in fact represented by gluing together the broken glass fragments and by introducing substantial post-breakage membrane effects. In the meanwhile, higher reaction loads must be transferred from the LG pane under blast to the window framing systems as well as to the building, which in return could lead to potential boundary failure mechanisms. Therefore, when LG panes are utilized for glass windows retrofit as well as novel constructions, strengthening of window frame members and fixing components is normally required. In principle, the concept of 'balanced design' should be generally followed, which means that - given a glass window or facade modular unit - in a blast incident the glass pane should fail before its boundary restraint (frame/mullion), so as to prevent the thorough failure of the window system which being propelled into the room.

\section{Interlayer Anchors}

Apart from strengthening window frames, interlayer anchors such as anchorage bolt or anchorage bar systems are commonly utilized to prevent pulling-out failure of LG panes when designing windows against blast loading (Fig. 9).
Extended interlayer strips of a given LG pane are left on purpose during the manufacturing phase, which are then clamped or anchored with bolts or bars into the window frame. Extra room is therefore required in the frame to inhabit anchors. Both field test and numerical modelling were recently performed to evaluated the structural effectiveness of such interlayer anchors (Trawinski et al., 2004; Zhang and Hao, 2015). Generally, it was proved that the vulnerability of LG windows with boundary failure could be effectively mitigated when proper interlayer anchorage is designed.

\section{Blast Curtains, Nets, Catching Systems}

Catching systems are a popular mitigation retrofit, in use together with LG panels for blast resistant design. The typical catch systems include catch bars, curtains, membranes (Trawinski et al., 2004). They are commonly installed behind glass windows, inside the building. The properly installed catching system could restrain the excessive deformation of LG pane and/or catch the flying glass fragments. As a key aspect of these solutions, however, proper anchorage is required to avoid system failure. Moreover, protection of personnel safety with the catching system is only effective to the residence inside the building whereas glass threat to personnel outside the room due to suction from negative pressure is difficult to achieve through installation of catching system. Beside the features of the specific solution, general rules for the classification of retrofitted techniques and quantification of their effects are still missing. As a result, a direct assessment of related benefits and a comparative discussion is not possible.

More in detail, blast curtains consist of special drapery systems, designed to mitigate flying glass shards and debris caused by bomb blast events (Fig. 10). Basically, the typical drape is aimed to protect lives by venting intense blast loads while safely capturing deadly flying projectiles and shards. High tenacity polyester ensure durability and resistance. Given an existing window, the drape is anchored at the head of the opening (either inside or outside mount), while remaining unanchored at the sill. Pressure from a blast unfurls the drape from the trough to create an envelope that captures flying debris. Once the blast pressure dissipates, the drape deposits the glass shards and debris on the floor at the base of the window. Experiments and calculations using ATB last Software by Applied Research Associates indicate that loads in the range of $25-380 \mathrm{kPa}$ can be sustained by glass windows ( $w w w$.wincos-global.com).

Blast nets, curtains and catchers are also intended to protect people inside buildings from exterior explosions. Differing from blast curtains, special nets are used to cover windows surfaces inside buildings and are aimed to catch and retain flying shards of glass, preventing the whole glass panels from being dislodged by blast wave (Fig. 11). 


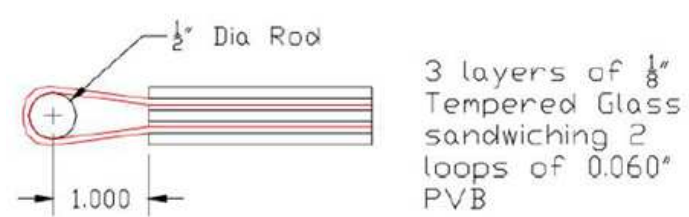

(a)

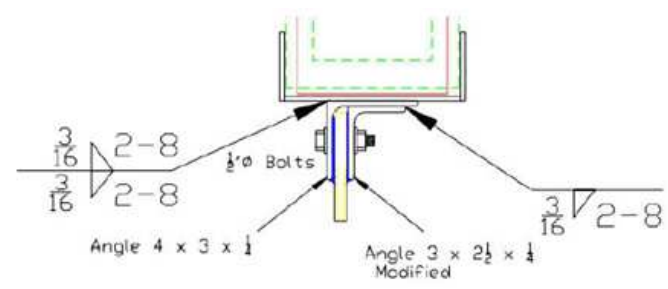

(b)

Fig. 9. Anchorage system for interlayer (Trawinski et al., 2004). (a) Anchor bar to PVB; (b) anchor bolt for PVB (note: nominal dimensions in inches)

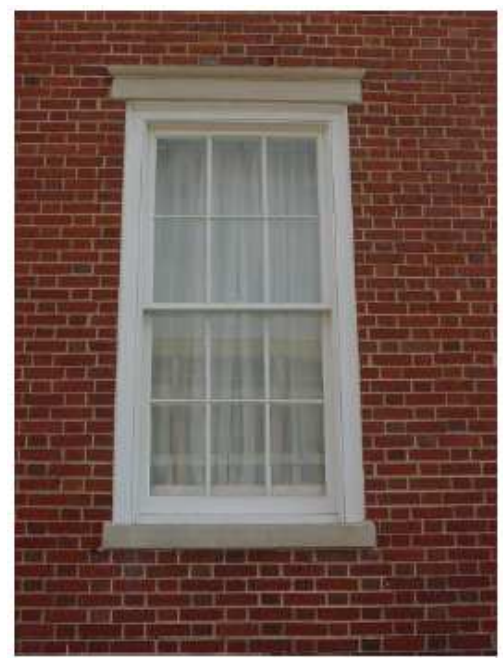

(a)

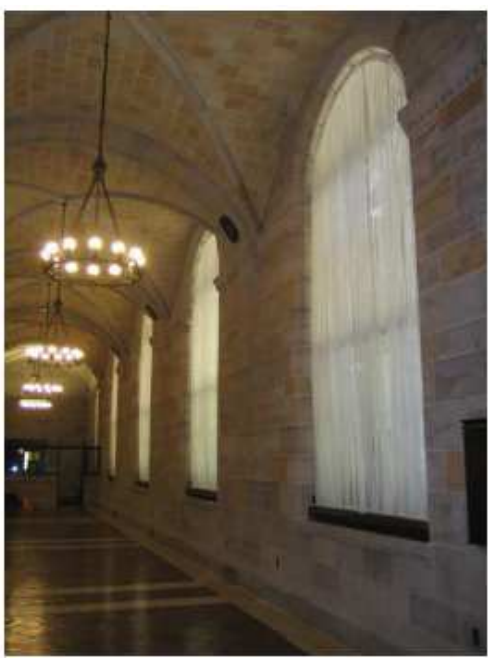

(b)

Fig. 10. Examples of application of blast curtains in residential or historical buildings (www.wincosglobal.com)

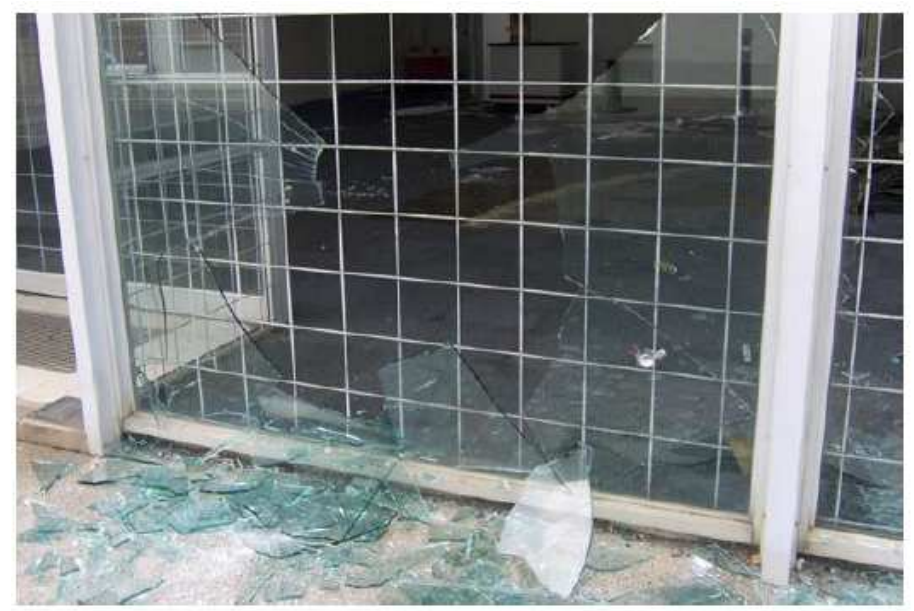

Fig. 11. Bomb blast net curtain: example of typical failure scenario after bombing

These systems are generally designed for vulnerable, high profile commercial and government buildings such as public buildings, military facilities, conference or religious centres. The typical bomb blast net can be made from white mesh polyester filament marquisette fabrics with $400 \mathrm{gsm}$ thickness. Solutions involving steel wire ropes having an energy-absorbing effect and diverting input blast forces are also available on the market. Given the cable net catcher geometry, in any case, a key role is then assigned to anchoring systems, so that their efficiency could be maximized. In (Remennikov and Brodie, 2002), for example, it was 
experimentally shown that catchers with fully rigid anchoring systems or special devices able to store part of the incoming impulse have a totally different performance under impact, with decrease of maximum blast-induced effects in the cables up of $-35 \%$ in the latter case. This finding is also in accordance with earlier analytical and finite element numerical research studies, see for example (Bedon and Amadio, 2014), where the design concept for special devices able to activate under impulsive loads only (hence to act as rigid restraints under ordinary loading conditions) was proposed for cable-supported glazing facades. The theoretical study follows some practical applications of similar methods, see for example (Wellershoff, 2008).

\section{Urethane Adhesives}

A further retrofitting technique which has been experimentally assessed during a past testing program carried out by the Army's Engineer Research and Development Center at the Waterways Experiment Station (Knox et al., 2000), consists in the use of automotive urethane adhesives. This technique proved to be very successful during the Tyndall AFB tests, see (Knox et al., 2000). There, $1 / 4$-inch LG panel was glued to a traditional aluminum frame, using automotive urethane adhesives in place of structural sealants of common use. While usually AN glass breaks up into large shards and daggers traveling at hundreds of meters per second or more, in Knox et al. (2000) it was successfully shown that - even after bombing test - the glass was shattered but retained into the supporting frame, hence resulting in no threat for people.

\section{Sliding Supporting Systems}

With more understanding on the response of LG panes under blast loading, as well as on the actual efficiency of new interlayer materials to improve the ductility and anti-tearing capacity of LG elements, various innovative blast mitigation retrofits have been introduced for glass windows/facades. For instance, a traditional LG pane equipped with 'sliding boundary' has been proposed in (Zhang and Hao, 2015), Fig. 12a, so to enable the transitional movement of the glass pane in the direction of blast wave and hence to relieve the applied blast pressure. In the case of double glazing units, a window frame with damping chamber was also proposed in (Trawinski et al., 2004), Fig. 12b, aiming to dissipate the blast energy through the vibration of the two glazing units as well as through pressure ventilation within the insulation chamber.

The design concept of special restraints able to act as passive control systems for enhanced glazing windows and facades has been also theoretically explored - even by considering different connection details - by several authors (Viefhues et al., 2014a; 2014b; Bedon and Amadio, 2016). The mentioned studies, including smallscale experiments, finite element numerical modelling, analytical calculations and design proposals, generally proved the efficiency of such control systems to replace ordinary fixings systems for glass windows and curtain walls under blast events and impact loading in general. Full development of such systems, including free-field validation of earlier research outcomes and standardization of design principles, is however still required.

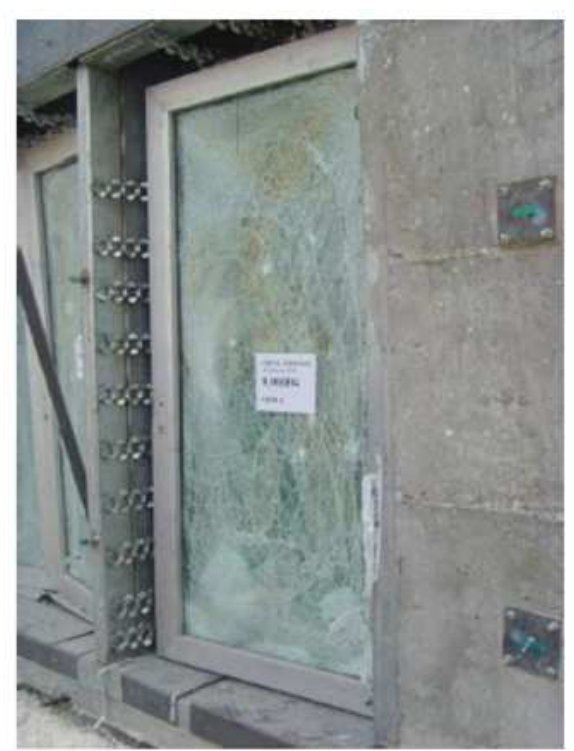

(a)

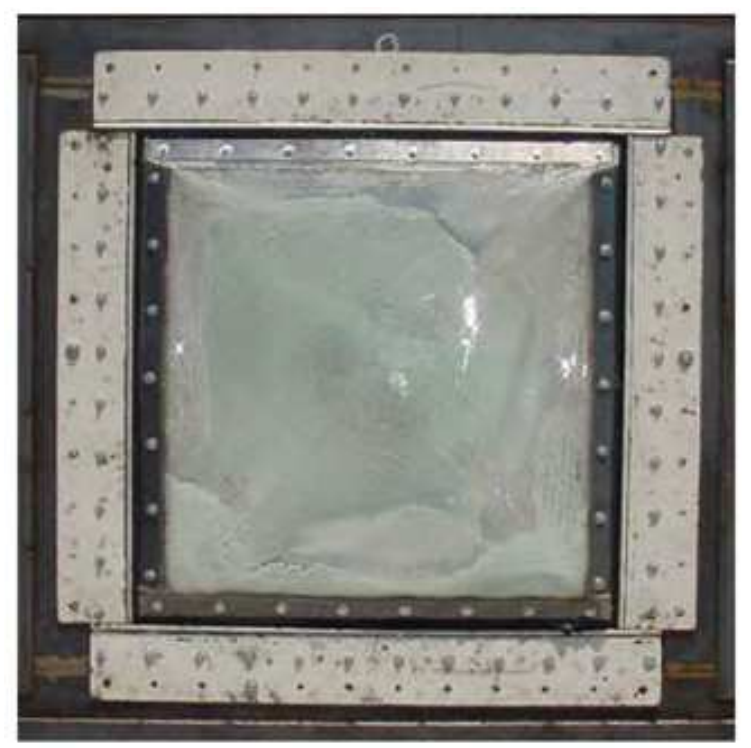

(b)

Fig. 12. Blast mitigation with new window frame system. (a) Punched windows with 'sliding boundary' (Zhang and Hao, 2015) and (b) damping chamber system (Trawinski et al., 2004) 


\section{Conclusion}

The continuously increasing use of glass in buildings, combined with the higher frequency of tragic accidental or human-induced blast events occurred in last year's, moved the attention of several research studies on the experimental, analytical and/or numerical investigation of glass windows and facades under explosive loads. Careful consideration was given to material dynamic characterization, as well as to the vulnerability assessment of full glazing assemblies under impact, or to the feasibility study of possible retrofitting techniques able to enhance the overall performance of glass systems exposed to high strain loads such as blast waves. In this study, a recapitulation of actually available research efforts was provided, with special evidence for experimental findings as well as current issues and trends for mitigating blast-related hazards on glass windows and curtains.

\section{Funding Information}

No funding was received for the manuscript.

\section{Author's Contributions}

Both the Authors actively contributed to literature research and manuscript draft.

\section{Ethics}

The Authors declare there's no conflict of interest.

\section{References}

ASTM E1300-09, 2009. Standard practice for determining the load resistance of glass in buildings. West Conshohocken, PA, USA.

ASTM F1642, 2004. Standard test method for glazing and glazing systems subject to air blast loadings. West Conshohocken, PA, USA.

ASTM F2248-09, 2009. Standard practice for specifying an equivalent 3 second duration design loading for blast resistant glazing fabricated with laminated glass. West Conshohocken, PA, USA.

Arrigoni, M., C. Bedon, A. van Doormal, C. Haberacker and G. Hüsken et al., 2017. Suggestions for adaptations of existing European norms for testing the resistance of windows and glazed façades to explosive effects. Alexander Stolz, European Union Publications Office, Technical Report (in print).

Bedon, C. and C. Amadio, 2014. Exploratory numerical analysis of two-way straight cable-net façades subjected to air blast loads. Eng. Struct., 79: 276-289. DOI: 10.1016/j.engstruct.2014.08.023
Bedon, C. and C. Amadio, 2016. Passive control systems for the blast enhancement of glazing curtain walls under explosive loads. Open Civil Eng. J., 10: 3-26. DOI: $10.2174 / 1874149501711010396$

Bedon, C. and C. Louter, 2014. Exploratory numerical analysis of SG-laminated reinforced glass beam experiments. Eng. Struct., 75: 4357-468. DOI: $10.1016 /$ j.engstruct.2014.06.022

Bedon, C., A. van Doormaal, C. Haberacker, G. Hüsken and M. Larcher et al., 2015. Recommendations for the Improvement of Existing European Norms for Testing the Resistance of Windows and Glazed Façades to Explosive Effects. Stolz, A. (Ed.), European Union Publications Office, Report EUR 27554 EN, ISBN-13: 978-92-79-53394-5.

Brown, W., 1974. A practicable formulation for the strength of glass and its special application to large plates. in Tech. Rep. Publication No. NRC14372, National Research Council of Canada, Ottawa.

BS EN 572-1, 2004. Glass in building: Basic soda lime silicate glass products. Definitions and general physical and mechanical properties, London, UK.

Feldmann, M., R. Kasper, B. Abeln, P. Cruz and J. Belis et al., 2014. Guidance for European Structural design of glass components-support to the implementation, harmonization and further development of the Eurocodes. Report EUR 26439, Joint Research Centre, Institute for the Protection and Security of the Citizen.

Fletcher, E.R., D.R. Richmond and J.T. Yelverton, 1980. Glass fragment hazard from windows broken by Airblast. DTIC Document.

Ge, J., G.Q. Li and S.W. Chen, 2012. Theoretical and experimental investigation on fragment behavior of architectural glass panel under blast loading. Eng. Failure Anal., 26: 293-303.

DOI: $10.1016 /$ j.engfailanal.2012.07.022

Gebbeken, N. and T. Bermbach, 2014. Protective glazing-a challenge to numerical simulation. Proceedings of the 6th International Conference on Protection of Structures against Hazards, (SAH' 14), Tianjin, China.

Griffith, A.A., 1921. The Phenomena of Rupture and Flow in Solids. Philosophical Transactions of the Royal Society of London. Series A, Containing Papers of a Mathematical or Physical Character (ArticleType: Research-Article/Full Publication.

GSA TS-01, 2003. Standard test method for glazing and window systems subject to dynamic overpressure loadings. General Services Administration, USA

Haldimann, M., A. Luible and M. Overend, 2008. Structural use of Glass. 1st Edn., IABSE, Switzerland, ISBN-10: 3857481196, pp: 215. 
Holmquist T.J., G.R. Johnson, D.E. Grady, C.M. Lopatin and E.S. Hertel Jr., 1995. High strain rate properties and constitutive modeling of glass. Proceedings of the 15th International Symposium on Ballistics, May 21-24, Jerusalem, Israel, pp: 234-244.

DOI: $10.2172 / 41367$

Hooper, P.A., R.A.M. Sukhram, B.R.K. Blackman and J.P. Dear, 2012. On the blast resistance of laminated glass. Int. J. Solids Struct., 49: 899-918. DOI: $10.1016 /$ j.ijsolstr.2011.12.008

HOSDB, 1997. Special services group, explosion protection. Glazing Hazard Guide-Charts, Security Facilities Executive; Report SSG/EP/3/97; Cabinet Office (Home Office Scientific Development Branch), London, UK.

Karlos, V. and G. Solomos, 2013. Calculation of blast loads for application to structural components. Administrative Arrangement $\mathrm{N}^{\circ}$ JRC 32253-2011 with DG-Home. Activity A5-Blast Simulation Technology Development, Technical Report.

Knox, K.J., M.I. Hammons, T.T. Lewis and J.R. Porter, 2000. Polymer materials for structural retrofit. Force Protection Branch, Air Expeditionary Force Technology Division, Air Force Research Laboratory, Tyndall Air Force Base, Fla, USA.

Kranzer, C., G. Gürke and C. Mayrhofer, 2005. Testing of bomb resistant glazing systems- experimental investigation of the time dependent deflection of blast loaded $7.5 \mathrm{~mm}$ laminated glass. Proceedings of the Glass Processing Days, (GPD’ 05), Tampere, Finland.

Iverson, J.H., 1968. Summary of existing structures evaluation part II: Window glass and applications. Office of Civil Defense, Office of the Secretary of the Army.

ISO 16933, 2007. Explosion-resistant security glazingtest and classification for Arena air-blast loading. International Organization for Standardization.

Larcher, M., M. Arrigoni, C. Bedon, J.C.A.M. van Doormaal and C. Haberacker et al., 2016. Design of blast-loaded glazing windows and facades: A review of essential requirements towards standardization. Adv. Civil Eng., 2016: 2604232-2604245. DOI: $10.1155 / 2016 / 2604232$

Larcher, M., G. Solomos, F. Casadei and N. Gebbeken, 2012. Experimental and numerical investigations of laminated glass subjected to blast loading. Int. J. Impact Eng., 39: 42-50.

DOI: 10.1016/j.ijimpeng.2011.09.006

Lin, L.H., E. Hinman, H.F. Stone and A.M. Roberts, 2004. Survey of window retrofit solutions for blast mitigation. J. Performance Constr. Facilities, 18: 86-94.

DOI: 10.1061/(ASCE)0887-3828(2004)18:2(86)
Meyer, S., L. Little and E. Conrath, 2004. Injury based glass hazard assessment. DTIC Document.

Meyers, G.E., D. Baldwin and P. Mlakar, 1994. State of the art of blast resistant windows. DTIC Document.

Moore, D.M., 1980. Proposed method for determining the thickness of glass in solar collector panels. NASA STI/Recon Technical Report N80-24755.

Morison, C., 2010. The resistance of laminated glass to blast pressure loading and the coefficients for single degree of freedom analysis of laminated glass. $\mathrm{PhD}$ Thesis, Cranfield University, UK.

Nie, X., W.W. Chen, X. Sun and D.W. Templeton, 2007. Dynamic failure of borosilicate glass under compression/shear loading experiments. J. Am. Ceramic Society, 90: 2556-2562. DOI: $10.1111 /$ j.1551-2916.2007.01819.x

Nie, X., W.W. Chen and D.W. Templeton, 2010. Dynamic ring-on-ring equibiaxial flexural strength of borosilicate glass. Int. J. Applied Ceramic Technol., 7: 616-624. DOI: $10.1111 / \mathrm{j} .1744-7402.2010 .02508 . x$

Peroni, M., G. Solomos, V. Pizzinato and M. Larcher, 2011. Experimental investigation of high strain-rate behaviour of glass. Applied Mechan. Mater., 82: 6368. DOI: 10.4028/www.scientific.net/AMM.82.63

Philip, E.B., 1945. Blast and the ministry of home security. Research and Expeirments Department, 1939-1945. Report No. REN 585, Ministry of Home Security.

Pritchard, D., 1981. Breakage of glass windows by explosions. J. Occupat. Accidents, 3: 69-85. DOI: 10.1016/0376-6349(81)90001-8

Remennikov, A.M. and L.S. Brodie, 2012. Experimental investigation of cable catcher systems for office building blast protection. Proceedings of the Australian Structural Engineering Conference, Jul. 11-13, Perth, West Australia, pp: 1-8.

Trawinski, E., J.W. Fisher and R.J. Dinan, 2004. Full scale testing of polymer reinforced blasting resistant windows. Air Force Research Laboratory, Florida, USA.

UFC 3-340-02, 2008. Structures to resist the effects of accidental explosions. US DoD, Washington, DC, USA.

Vallabhan, C.V.G. and G.D. Chou, 1986. Interactive Nonlinear Analysis of Insulating Glass Units. ASCE J. Struct. Eng., 112: 1313-1326. DOI: 10.1061/(ASCE)0733-9445(1986)112:6(1313)

van Doormaal, A., J. Weerheijm and M. Rhijnsburger, 2009. Hazard of glazing due to blast loading. Proceedings of the International Symposium on Interaction of the Effects of Munitions with Structures, (EMS' 09), Florida, USA. 
Viefhues, E., M. Unal, G. Hüsken, M. Mehdianpour and F. Wellershoff, 2014a. Zementgebundenes Crashmaterial für Schutzbauteile in explosionsbeanspruchten Fassaden. Bautechnik, 9: 567- 571. DOI: 10.1002/bate.201400041

Viefhues, E., F. Wellershoff and M. Mehdianpour, 2014b. Energiedissipierende Fassadenverankerung mit Crashmaterial für explosionsbeanspruchte Gebäude. Bautechnik, 91: 561-566. DOI: $10.1002 /$ bate. 201400042

Weissman, S., N. Dobbs, W. Stea and P. Price, 1978. Blast capacity evaluation of glass windows and aluminum window frames. DTIC Document.

Wellershoff, F., 2008. Blast enhanced facades for the new world trade centre towers NY. Proceedings of the Challenging Glass Conference, (CGC' 08), pp: 643-653.

Wightman, J.M. and S.L. Gladish, 2001. Explosions and blast injuries. Annals Emergency Med., 37: 664-678. DOI: 10.1067/mem.2001.114906

Yeh, D.D. and W. Schecter, 2012. Primary blast injuriesan updated concise review. World J. Surgery, 36: 966-972. DOI: 10.1007/s00268-012-1500-9

Zhang, X. and H. Hao, 2015. Experimental and numerical study of boundary and anchorage effect on laminated glass windows under blast loading. Eng. Struct., 90: 96-116.

DOI: $10.1016 /$ j.engstruct.2015.02.022
Zhang, X., H. Hao and Z. Wang, 2014. Experimental investigation of monolithic tempered glass fragment characteristics subjected to blast loads. Eng. Struct., 75: 259-275. DOI: 10.1016/j.engstruct.2014.06.014

Zhang, X., H. Hao and Z. Wang, 2015a. Experimental investigation on monolithic tempered glass window responses to blast loads. Int. J. Protective Struct., 6: 287-309. DOI: 10.1016/j.engstruct.2014.06.014

Zhang, X., H. Hao and Z. Wang, 2015b. Experimental study of laminated glass window responses under impulsive and blast loading. Int. J. Impact Eng., 78: 1-19. DOI: 10.1016/j.ijimpeng.2014.11.020

Zhang, X., H. Hao, Y. Shi and J. Cui, 2015c. The mechanical properties of Polyvinyl Butyral (PVB) at high strain rates. Constr. Build. Mater., 93: 404-415. DOI: 10.1016/j.conbuildmat.2015.04.057

Zhang, X., Y. Shi, H. Hao and J. Cui, 2015d. The mechanical properties of ionoplast interlayer material at high strain rates. Mater. Design, 83: 387-399. DOI: 10.1016/j.matdes.2015.06.076

Zhang, X., Y. Zou, H. Hao, X. Li and G. Ma et al., 2012. Laboratory test on dynamic material properties of annealed float glass. Int. J. Protective Struct., 3: 407-430. DOI: 10.1260/2041-4196.3.4.407 